\title{
Analysis of Students' Mathematical Reasoning Ability in Solving Mathematics Problem
}

\author{
Ratih Dewi Rahmawati \\ Dept. of Mathematics Education \\ Univerisitas Sebelas Maret \\ Surakarta, Indonesia \\ dratihdewi14@gmail.com
}

\author{
Mardiyana \\ Dept. of Mathematics Education \\ Univerisitas Sebelas Maret \\ Surakarta, Indonesia \\ mardiyana@staff.uns.ac.id
}

\author{
Triyanto \\ Dept. of Mathematics Education \\ Univerisitas Sebelas Maret \\ Surakarta, Indonesia \\ triyanto@fkip.uns.ac.id
}

\begin{abstract}
The purpose of this study is to describe students' mathematical reasoning abilities in solving mathematical problems. This study used descriptive qualitative method. The subjects of the study consisted of 10 XI grade students of SMA Muhammadiyah 3 Surakarta, selected by purposive sampling. The instrument used to explore the ability of mathematical reasoning is a description test, followed by an interview. Based on the results of this study it can be concluded that the reasoning of SMA Muhammadiyah 3 Surakarta students in solving mathematical problems is more dominant using inductive reasoning of $70 \%$, which is far greater than deductive reasoning which is only $30 \%$. Another interesting finding from this study, students tend to use the inductive reasoning and the difficulty or not thought of using deductive reasoning in solving mathemathics problem, but when interviews are given guidance it turns out that some of them are capable of using deductive reasoning. The tendency of inductive reasoning, associated with students who are easier to think with real specific facts in solving abstract mathematics problems. This inductive reasoning is formed because inlearning, to facilitate students' understanding in the mastery of abstract mathematical concepts, the teacher provides spesific concrete examples to conclude a more general concept. To build a deductive mindset, it should teach an understanding of bastract mathematical concepts, although starting from a spesific example but the teacher must deliver gradually so that the correct logic can conclude a general concept.
\end{abstract}

Keywords-mathematics problem solving, mathematics reasoning, deductive, inductive

\section{INTRODUCTION}

Indonesia attemped to become a developed country with other developed countries, especially in education. As the times progressed, the process of becoming a developed country in science and technology required students to have a high sense of reasoning. Student's high reasoning will be a qualified human resource. Qualified human resources will be more competent in the global era. The learning activities of mathematics in schools should refer to the 4 characters of the 21 st century learning formulated in 4C are Communication, Collaboration, Critical
Thinking and Problem Solving, Creativity andInnovation [1]. [2] Teguh Wibowo stated that mathematics has a very close relationship with reasoning. Mathematical knowledge also has a basis in reasoning [3]. According to [4] reasoning is defined as the process of drawing conclusions on the basis of evidence or assumed assumptions. Another definition of reasoning as an action uses reason to derive conclusions from a particular place. Generally, differences are made between reasoning from the general to the particular or called deductive reasoning. Reasoning from the special to the common or called inductive reasoning [5].

Mathematical reasoning is important because it makes unique features applied in mathematics as a subject. Once students are able to apply some of the unique features of mathematics, then they are able to solve problems that require them to generalize, apply abstract thinking and also simplify. Therefore, mathematical reasoning is very useful for solving problems [6]. McKenzie [7] argues that understanding in mathematics is based on mathematical reasoning. Muller \& Maher [4], Mathematical understanding depends on reasoning and reasoning is very important for a student to grow in mathematical knowledge. Students who have a mathematical reasoning can apply mathematical ideas with a developed problem solving skills.

Problem solving in mathematics, evidence is a convin-cing argument in accepted mathematical standards that some mathematical statements are true. The evidence is derived from deductive reasoning, not from inductive or empirical arguments [8]. The proof must indicate that the statement is true in all cases, without a single exception. In other words, mathematical evidence should apply to all cases [9].

Yopp [10] argues, there are two type of reasoning: deductive and inductive reasoning. Deductive reasoning is a logical process of thinking in which something is known and everyone agrees that it is properly applied to a particular case. In contrast, inductive reasoning is a logical process in which a learner proceeds from a particular proof to a conclusion, which has been viewed as true [11]. In 
other words, inductive reasoning is generally used to prove or define that the given statement is true. Mill [12] states that the induction of an activity in which we conclude that what we know is true for special cases will also apply to similar cases for certain things. While deductive reasoning is a way to draw conclusions from statements or facts that are considered correct using logic. This reason tends to use theory or formula that has been proven to be true deductively.

The deductive and inductive reasoning is part of the student's character. The character of the student develops in the learning process of mathematics. Students are given deductive and inductive reasoning patterns in accordance with the development of intelligence. The deductive and inductive reasoning is applied in problem solving, especially the habit of solving problems in mathematics. The importance of problem solving is affirmed in the National Council of Teachers of Mathematics (NCTM) [13] that problem solving is an integral part of mathematics learning. The learning process has a purposeful standard develop students' mathematical reasoning abilities and learn to solve problems. According to [3] mathematical reasoning does not have to be proof, but all the explanatory forms used to construct convincing arguments can be included in mathematical reasoning. In addition, mathematical reasoning involves the execution of mathematical practice in the way that creators and users of mathematics do: justify, make guesses, explain, challenge, and solve problems.

Arslan [14] said the fact the mathematics education students' make more reference to the deduction might be interpreted to the familiarity of these students to formal mathematical structure. Based on the experience that has been happening in the field, it appears that the students did not develop much deductive reasoning that he had obtained from the teacher. Through learning, students are trained to make generalizations. To reach the generalization stage, it is necessary to understand the relationship or linkage for the given example, the problem-solving plan, the calculation process, and the process to verify the results obtained. These elements are indicators of mathematical problem-solving abilities. In fact on the field students are more likely to come up with statement statements that are summarized for all general statements. This is due to teachers who do not em-phasize students' reasoning ability in solving mathematical problems..

\section{RESEARCH METHOD}

This research is descriptive qualitative research. According to [15] qualitative research is a study that intends to understand the phenomenon of what is experienced by research subjects, such as behavior, perception, motivation, action, etc. holistically and by way of description in the form of words and language, on a special context that is natural and by utilizing various scientific methods. The research was conducted on April 10, 2018 until May 25, 2018. The subjects in this study consisted of ten students of class
XI SMAMuhammadiyah 3 Surakarta who have been selected using purposive sampling with the consideration of subjects who can provide optimal information in accordance with research objectives.

The instruments used in this study consist of the main instrument, the researcher himself, and supporting instruments in the form of reasoning tests, observation sheets, and interview guides. To obtain the validity of optimal research data, it has been done with triangulation method and source triangulation. Triangulation method uses two methods namely test and interview method, while triangulation of source done in interview stage involving teacher and student. Stages of data analysis have been done as follows: (1) data collection, (2) data reduction (3) data presentation, (4) data analysis, and (5) conclusion.

\section{RESULT AND DISCUSSION}

First stages in this study are to have devised a mathe-matical reasoning test instrument that is expected to provide an overview of students' reasoning in solving mathematical problems, namely deductive or inductive. [14] provides an explanation of the character of deductive and inductive reasoning as presented in Table 1 as follows

TABLE I. THE DIFFERENCES OF DEDUCTIVE INDUCTIVE REASONING

\begin{tabular}{|c|c|}
\hline $\begin{array}{l}\text { Indicators of Deductive } \\
\text { Reasoning } \\
\end{array}$ & $\begin{array}{c}\text { Indicators of Inductive } \\
\text { Reasoning } \\
\end{array}$ \\
\hline $\begin{array}{l}\text { General statement to a } \\
\text { special statement }\end{array}$ & $\begin{array}{l}\text { A special statement to the general } \\
\text { statement. }\end{array}$ \\
\hline $\begin{array}{l}\text { Abstract statement to the } \\
\text { concrete }\end{array}$ & $\begin{array}{c}\text { Concrete statements toward the } \\
\text { abstract }\end{array}$ \\
\hline $\begin{array}{l}\text { A rational statement to the } \\
\text { empirical world }\end{array}$ & Empirical statement toward rational \\
\hline $\begin{array}{c}\text { Indicators of Deductive } \\
\text { Reasoning }\end{array}$ & $\begin{array}{c}\text { Indicators of Inductive } \\
\text { Reasoning }\end{array}$ \\
\hline $\begin{array}{l}\text { Must master the science } \\
\text { concerned }\end{array}$ & $\begin{array}{c}\text { Must be able to see, choose and } \\
\text { determine relevant facts }\end{array}$ \\
\hline $\begin{array}{l}\text { Using mathematics as a } \\
\text { means of thinking }\end{array}$ & $\begin{array}{c}\text { Using statistics as a means of } \\
\text { thinking }\end{array}$ \\
\hline $\begin{array}{l}\text { Using population data for } \\
\text { final conclusions }\end{array}$ & $\begin{array}{l}\text { Using sample data to summarize } \\
\text { the entire population data }\end{array}$ \\
\hline
\end{tabular}

Based on the results of data analysis that has been obtained through reasoning tests followed by interviews, has obtained the percentage of mathematical reasoning pattern of SMA Muhammadiyah 3 Surakarta students as presented in figure 1 as follows.

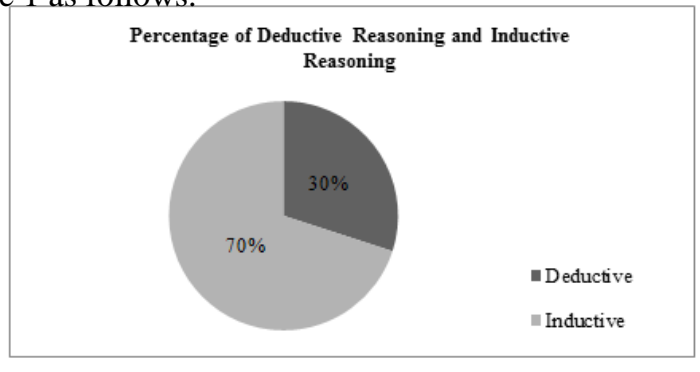

Fig. 1. Percentage of students' deductive and inductive reasoning 
Take notice Figure 1, it can be seen that the percentage of students who are able to solve the problem with inductive reasoning is $70 \%$, which is much greater than deductive reasoning which is only $30 \%$. To explore more in the analysis of students' reasoning, both the factors and their implications in learning are based on test results, interviews, and observations.

The results of the in-depth analysis of each problem solving mathematics is described as follows.

Number 1: Prove the number of two odd numbers is even. takes a sample of several numbers to be concluded in the odd number population. Alleged students who draw conclusions from incomplete evidence. This is true based on the available evidence, but it has not been officially proven. Interviews with $\mathrm{S} 1$ show different results, as students are given few clues to the direction of deductive reasoning and students are able to complete with deductive reasoning. S2 has been able to solve mathematical problems with deductive reasoning, using the definition of numbers. S2 has taken the odd number in general and summed up for the odd number population, so it can apply to all cases.

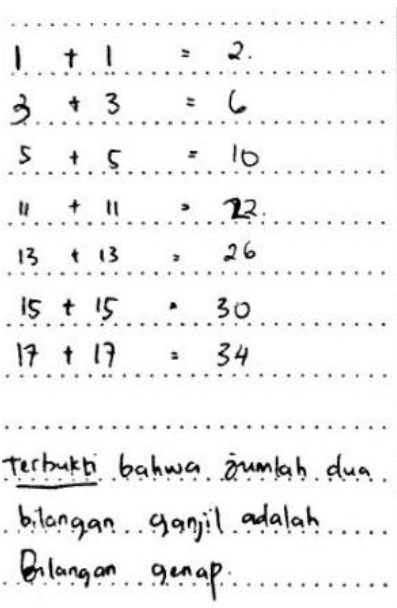

Fig. 2. Answer S1

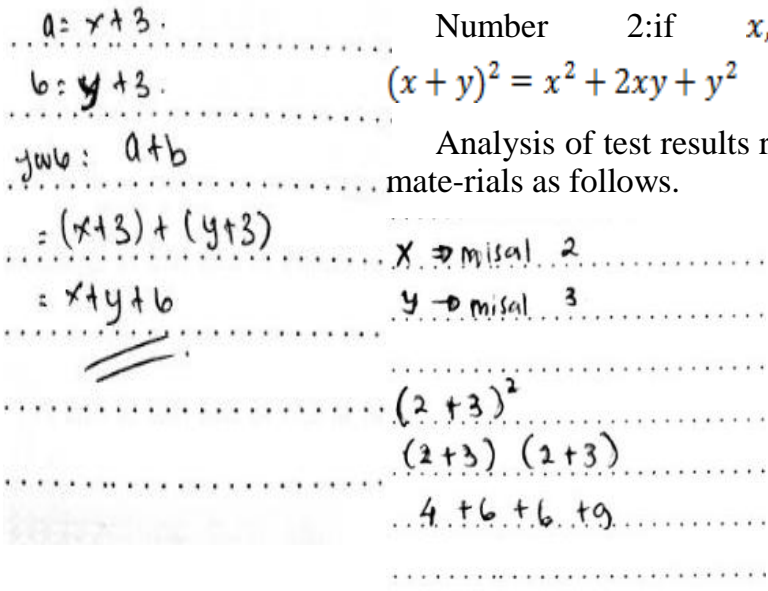

Fig. 3. Answer S2
The student has solved the problem on the number matter with the inductive mindset. This can be seen in student work. The student has taken the course to solve the problem, by entering the numbers directly and concluding for all the odd number is even. The student proves that the sum of two odd numbers is even by specifying $1+1=2,3+3=6$. Has com-pleted the interview after to reinforce the following information.

$\mathrm{R}$ : "Is there any difficulty while working on the problem?"

S1: "Nothing, I think it's an easy matter."

$\mathrm{R}$ : "S1 why has it directly substituted the number $1+1=2$ ?"

S1: "Yes indeed $1+1=2$, that answer has answered the question."

$\mathrm{R}$ : "Is there any other way to solve the problem?"

$\mathrm{S} 1$ : "I do not know. I have solved the problem in that way."

$\mathrm{R}$ : "How with I give an odd number $\mathrm{a}=\mathrm{x}+1$ and $\mathrm{b}$ $=\mathrm{y}+1$ with $\mathrm{a}, \mathrm{b} \in \mathrm{R}$ ?

S1: " $\mathrm{A}$ and $\mathrm{b}$ are odd numbers, then if summed $\mathrm{a}+\mathrm{b}=$ $(x+1)+(y+1)=x+y+2 . "$

$\mathrm{R}$ : "What is the conclusion of the settlement?"

S1: "The sum of two odd numbers is even"

S1 has solved a mathematical problem on a number problem with an inductive reasoning pattern, is using a specific case to generalize for all cases. S1
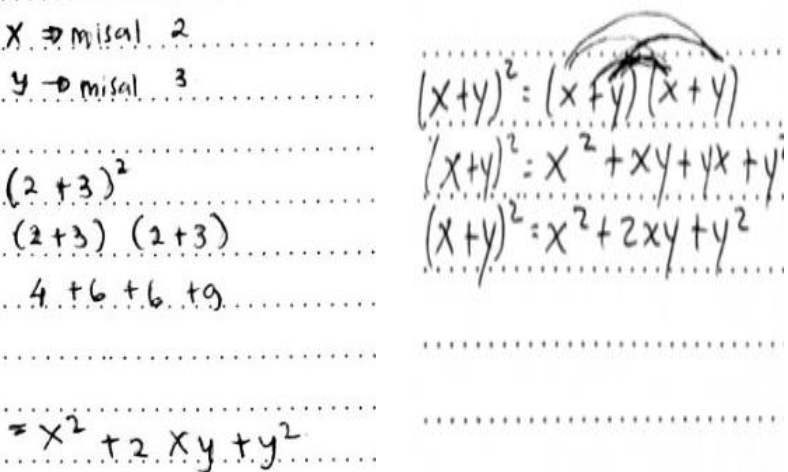

$=x^{2}+2 x y+y^{2}$

$\rightarrow$ Terbukt bahwa

$(x+y)^{2}=x^{2}+2 x y+y^{2}$

Fig. 4. Answer S3

Fig. 5. Answer S4

Students have solved the problem on algebra material with inductive mindset. Student work on this is the same as solving the problem by taking $x=2$ and $y=2$. The student has proved $(x+y)^{2}=x^{2}+2 x+y^{2}$ with substituted $x=2$ and $y=2$ in solving algebraic problems. Has completed the interview after to reinforce the following information.

$\mathrm{R}$ : "Is there any difficulty while working on the problem?"

S3: "Nothing. I have understood the problem."

$\mathrm{R}$ : "Why directly take the numbers 2 and 3?"

S3: "Because having taken the numbers has been able to solve the problem on the matter."

$\mathrm{R}$ : "Is there any other way to answer the question?"

S3 : "Maybe, the other way with change the numbers."

$\mathrm{R}$ :"Can you continue if I give directions to $(x+y)^{2}=(x+y)(x+y) ?$ 
$\mathrm{S} 3:$ " $x^{2}+x y+x y+y^{2}$."

$\mathrm{R}$ : "Is it possible to answer that question?"

S3 : "Yes, I think."

S3 has solved mathematical problems on algebra problems with inductive reasoning patterns, using specific cases to generalize for all cases. Interview result with S3 are different thing, because students have been given little clue to the direction of deductive reasoning students are able to finish with deductive reasoning. S3 has sampled several numbers and substitutes into the algebraic function equation. Alleged students who have drawn conclusions from incomplete evidence, and that is true based on existing evidence, but has not been officially proven. Interviews with S3 show different results, because students are given few clues to the direction of deductive reasoning and students are able to complete with deductive reasoning. S4 has been able to solve mathematical problems with deductive reasoning patterns, using algebraic definitions and rules. S4 works in general so it applies to all cases.

Beginning students have given a special statement to conclude with the general statement. It shows an inductive student mindset. By interviewing students are fished to think deductively in solving problems and students are able to solve them. Students need to understand the structure of deductive evidence if they want to gain an understanding of, and ability with, how to build evidence. The student already has a deductive reasoning pattern. Same with the definition of Johnston, [11] that deductive reasoning is a process of logical thinking in which something is known and everyone agrees that it is truly applied to a particular case. Instead of inductive reasoning is a logical process in which a learner proceeds from a particular proof to a conclusion, which is regarded as true.

The results of interviews and observations that have been done in the learning, student reasoning patterns more formed on inductive reasoning. This has been obtained because in learning, to facilitate students' understanding in the mastery of abstract mathematical concepts, the teacher provides specific concrete examples to conclude a more general concept. To build a deductive mindset, it should teach an understanding of abstract mathematical concepts, although starting from a specific example but the teacher must deliver gradually so that the correct logic can conclude a general concept.

\section{CONCLUSION}

Based on the results of this study it can be concluded that the reasoning of SMA Muhammadiyah 3 Surakarta students in solving mathematical problems is more dominant using inductive reasoning of $70 \%$, which is far greater than deductive reasoning which is only $30 \%$. Another interesting finding from this study, students tend to use inductive reasoning and the difficulty or not thought of using deductive reasoning in solving mathematical problems, but when interviews are given guidance it turns out that some of them are capable of using deductive reasoning.

The tendency of the use of inductive reasoning, associated with students who are easier to think with specific facts that are real in solving mathematical problems. This inductive reasoning is formed because in learning, to facilitate students' understanding in the mastery of abstract mathematical concepts, the teacher provides specific con-screte examples to conclude a more general concept. To build a deductive mindset, it should teach an understanding of abstract mathematical concepts, although starting from a specific example but the teacher must deliver gradually so that the correct logic can conclude a general concept.

\section{REFERENCES}

[1] Trilling and Fidel, 21st century Skills: Learning For Life In Our Times. Jossey Bass: USA, 2009

[2] T. Wibowo, "Adaptive Reasoning Junior High School Students In Mathematics Problem Solving,” 2016.

[3] B. Aineamani, "Reasoning and Communicating Mathematically," vol. 1, 2010, pp. 171-183.

[4] M. Muller and C. Maher, "Learning to Reason in An Informal Math After-School Program,”vol. 21(3), 2009, pp. 109-199.

[5] Webster Dictionary, Retrieved Maret 5, 2018, from http://www.websters-online-dictionary.org. 2003.

[6] J. Kilpatrick, J. Swafford, and B. Findell, "(Eds). Adding it up: Helping children learn mathematics,” 2001, pp 115-155.

[7] F. McKenzie, "Developing children's communication skills to aid mathematical understanding," 11, 2001.

[8] A. Selden, and J. Selden, "Validations of Proofs Considered as Texts: Can Undergraduates Tell Whether an Argument Proves a Theorem?,"vol. 34 No 1, 2003, pp. 4-33.

[9] L. Healy, and C. Hoyles, "A study of Proof Conceptions in Algebra,” vol. 31 No 4, 2000, pp. 396-428.

[10] D. A. Yopp, "From Inductive Reasoning To Proof," vol. 15 No 5, 2010, pp. 286- 291.

[11] I. Johnston, Essays and Arguments. British Colombia: Malaspina, 2002.

[12] J. S. Mill, On Liberty: Perihal Kebebasan (terjemahan oleh Alex Lenur), yayasan Obor Indonesia. Jakarta, 2005.

[13] NCTM, Principles and Standards for School Mathematics. United States of America: The National Council of Teachers of Mathematics, Inc, 2000.

[14] C. Arslan, S. L. Gocmencelebi, and M. S. Tapan, "Learning and Reason Styles of Pre Service Teacher': Inductive Or Deductive Reasoning On Science Style,” 2009.

[15] L.J. Moleong, Qualitative Research Methodology. Bandung: Rosdakarya, 2012.

[16] W. Winarso, "Building Higher Thinking Skills Through Inductive, Deductive and Inductive-Deductive Approaches in Mathematics Learning," vol. 3 No 2, 2014. 